\title{
SYNTHESIS OF $\mathrm{NiFe}_{2} \mathrm{O}_{4}$ NANOFIBERS BY JOINT SOL-GEL AND ELECTROSPINNING TECHNIQUE
}

\author{
Aleksandar Grujićl, ${ }^{1}$ Vladan Ćosovic ${ }^{1 *}$, Jasna Stajić-Trošić ${ }^{1}$, Aleksandar \\ Ćosović ${ }^{2}$, Mirko Stijepovićn ${ }^{2}$ Lana Putićl ${ }^{1}$,Tomáś Žák \\ ${ }^{1}$ Institute of Chemistry, Technology and Metallurgy, University of Belgrade, \\ Belgrade, Serbia \\ ${ }^{2}$ Faculty of Technology and Metallurgy, University of Belgrade, Belgrade, \\ Serbia \\ ${ }^{3}$ Institute of Physics of Materials of the Czech Academy of Sciences, Brno, \\ Czech Republic
}

Received 28.09.2018

Accepted 11.10.2018

\begin{abstract}
In this study, electrospinning combined with sol-gel technique is applied in order to produce magnetic nickel ferrite (Ni-ferrite) nanofibers. The prepared Ni-ferrite gel was mixed with poly(vinylpyrrolidone) (PVP) solution which was used as a spinning aid to enable spinnability of the mixture. Structural and morphological characteristics of the asspun ferrite gel/PVP composite web structure and calcinated Ni-ferrite nanofibers were analyzed using scanning electron microscopy (SEM). Phase composition analysis was carried out by Fourier-transform infrared (FT-IR) spectroscopy, X-Ray diffraction analysis (XRD) and ${ }^{57} \mathrm{Fe}$ Mössbauer spectroscopy (MS). The obtained results suggest that the pure nanocrystalline $\mathrm{NiFe}_{2} \mathrm{O}_{4}$ dense mat to the almost coral-like structure of fibers with diameters ranging from hundreds of nanometers to few micrometers was obtained. The results of MS analysis revealed the existence of a crystallite size distribution within the material as well as the existence of a superparamagnetic fraction with very small crystallite sizes $(<13 \mathrm{~nm})$. Magnetic behavior of the obtained material at elevated temperatures was also scrutinized using thermomagnetic measurements (TM) up to $800{ }^{\circ} \mathrm{C}$.
\end{abstract}

Keywords: Ni-ferrite; sol-gel; electrospinning, nanofibers; thermomagnetic behavior.

\footnotetext{
* Corresponding author: Vladan Ćosović, vlada@tmf.bg.ac.rs
} 


\section{Introduction}

For many years magnetically soft ferrites with a cubic spinel, lattice structure have been commonly used in various applications [1,2]. Some of the critical properties of the soft magnetic materials such as nickel ferrite are the high electrical resistivity on one side and the low magnetocrystalline anisotropy on the other. These provide an excellent core material applicable in power transformers in electronic and telecommunication applications [3]. On the other hand, it is known that the nanostructured materials usually have significantly different properties compared to their bulk form [4]. Rapid development of nanoscience and nanotechnology in recent years has created great interest in these materials, particularly in one dimensional and quasi-one-dimensional magnetic nanostructured materials such as nanofibers, nanotubes, nanowires, nanowhiskers, etc. [5]. As aforementioned, this is primarily due to their unique chemical and physical properties and a large surface to volume ratio that offers substantial potential for fabrication and design of innovative electromagnetic devices, sensing elements and catalysts.

Electrospinning is one of the most common methods for polymer nanofiber production [6]. Using this method nanofiber nets are obtained by electrically charging a suspended droplet of a solution. An additional advantageous feature of this method is that it provides a possibility for the preparation of inorganic fibers, webs or mats by the simple addition of appropriate precursors to the polymer solution. Electrospun magnetic nanofibers are especially interesting because they are comparatively inexpensive and easy to produce with the desired diameter and with modified composition and/or surface [2]. Appropriately selected starting parameters provide the desired thickness, composition and porosity of the produced nanofibers mat. The thickness of the produced fibers, i.e. their diameters are usually between 2-3 nm up to a few micrometers [7].

In the present study, $\mathrm{Ni}$-ferrite $\left(\mathrm{NiFe}_{2} \mathrm{O}_{4}\right)$ magnetic nanofibers/net were prepared using a preparation approach adopted from literature [8] which represents a combination of electrospinning [9] and a sol-gel method [10]. Using broad spectra of literature and applying different high-resolution methods of characterization the obtained material was subsequently scrutinized regarding its morphology, structure, phase composition and thermomagnetic behavior.

\section{Experimental}

Synthesis

Aqueous solutions of $\mathrm{Ni}\left(\mathrm{NO}_{3}\right)_{2} \times 6 \mathrm{H}_{2} \mathrm{O}$ and $\mathrm{Fe}\left(\mathrm{NO}_{3}\right)_{3} \times 9 \mathrm{H}_{2} \mathrm{O}$ were selected as starting materials for the ferrite sol. Citric acid was applied as a chelating agent. The $\mathrm{pH}$ value is maintained constant with the addition of ammonium hydroxide. After the subsequent water removal, the ferrite gel was obtained.

Afterward, a solution for electrospinning process was prepared by mixing the ferrite gel with a solution of polyvinylpyrrolidone (PVP) in acetic acid. The PVP was added to provide sufficiently high viscosity and to enable spinnability of the mixture, essentially. The nanofibers were produced using an electrospinning apparatus with plate collector and the vertical configuration the allowed the production of nanoweb statically. The electrospinning process was carried out using one syringe with a set solution flow rate of $0.5 \mathrm{ml} / \mathrm{h}$ under the applied voltage of $28 \mathrm{kV}$. The distance between the electrode and the needle tip was $15 \mathrm{~cm}$. After drying, the as-spun fibers were calcinated for $5 \mathrm{~h}$ at 
$700{ }^{\circ} \mathrm{C}$. During this process, organic components were removed. Also, a reaction between present oxides which produces $\mathrm{Ni}$-ferrite magnetic nanofibers was initiated.

The mechanism of the applied experimental procedure is presented in Fig. 1. The produced electrospun ferrite/PVP web is transformed into ferrite nanofibers mat after thermal treatment. The parameters of the calcination process were selected after a set of experiments.

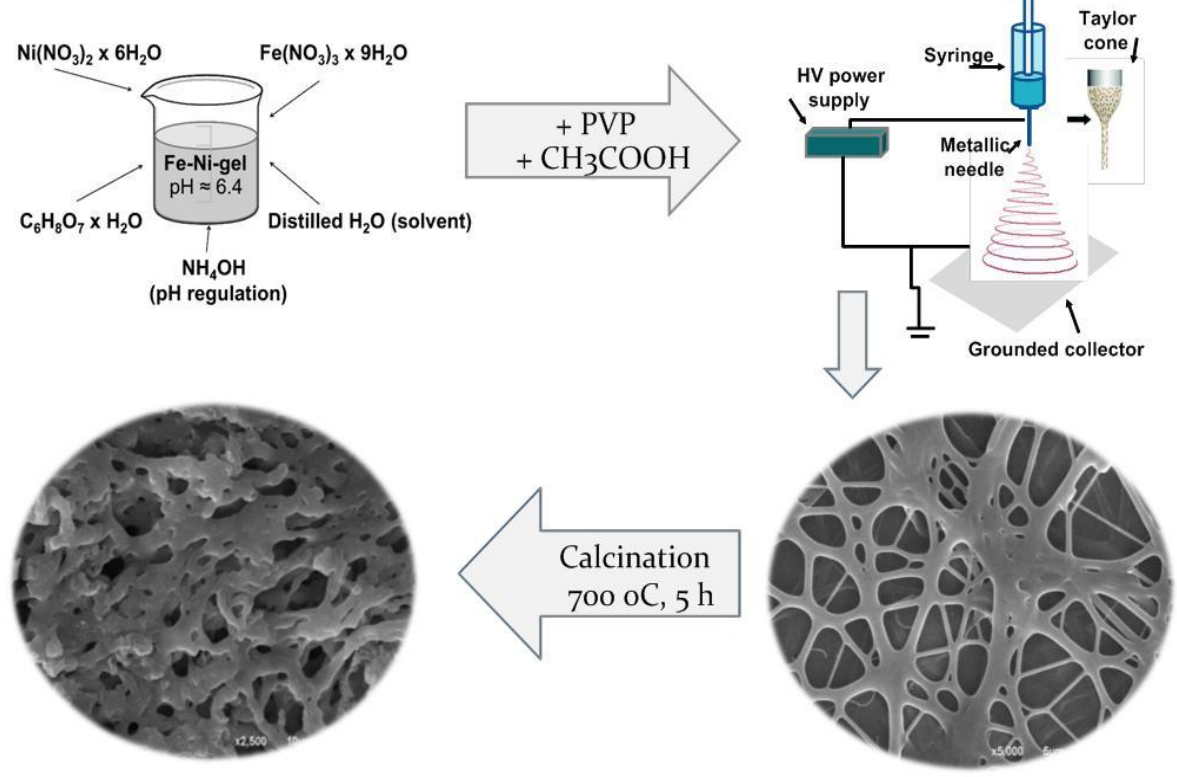

Fig. 1. The production route of $\mathrm{NiFe}_{2} \mathrm{O}_{4}$ nanofibers mat.

\section{Characterization}

Morphology and microstructure of the electrospun composite fibers before calcination and of the calcinated $\mathrm{NiFe}_{2} \mathrm{O}_{4}$ magnetic fibers were studied using JEOL JSM 6610LV scanning electron microscope (SEM). Phase composition was determined using Fourier-transform infrared (FT-IR) spectroscopy, X-Ray diffraction analysis (XRD) and ${ }^{57} \mathrm{Fe}$ Mossbauer spectroscopy (MS). All phase composition analyzes were carried out at ambient temperature. FT-IR spectra of the nanofibres were recorded by a BOMEM spectrometer (Hartmann \& Braun, MB series) with $4 \mathrm{~cm}^{-1}$ resolution, using a transmission mode between 4000 and $400 \mathrm{~cm}^{-1}$. XRD diffraction patterns were obtained using PANanalytical X'Pert PRO MPD X-ray diffractometer with CoK $\alpha$ radiation. The XRD pattern fitting was done using Full Prof software and ICDD database. Mössbauer spectra were taken at room temperature in the standard transmission geometry using a ${ }^{57} \mathrm{Co}(\mathrm{Rh})$ source. The calibration was done against an $\alpha$-Fe foil, and the CONFIT software package was used for MS spectra analysis [11]. With the aim of gaining better insight into the magnetic behavior of the obtained $\mathrm{NiFe}_{2} \mathrm{O}_{4}$ nanofibers/mat at elevated temperatures, thermomagnetic measurements (TM) were carried out. The thermomagnetic curves were recorded on $E G \& G$ vibrating sample magnetometer using 
the field strength of $4 \mathrm{kAm}^{-1}$ in a vacuum. The applied heating and cooling rate was $4^{\circ} \mathrm{C}$ $\mathrm{min}^{-1}$ with 30 min delay at the maximum of $800^{\circ} \mathrm{C}$.

\section{Results and discussion}

SEM micrographs presented on Fig. 2 illustrates the structure and morphology of the electrospun ferrite gel/PVP composite fibers after drying. The obtained structure looks like a porous fiber web with fibers of micron to submicron diameters that crisscross the surface of the collector plate.
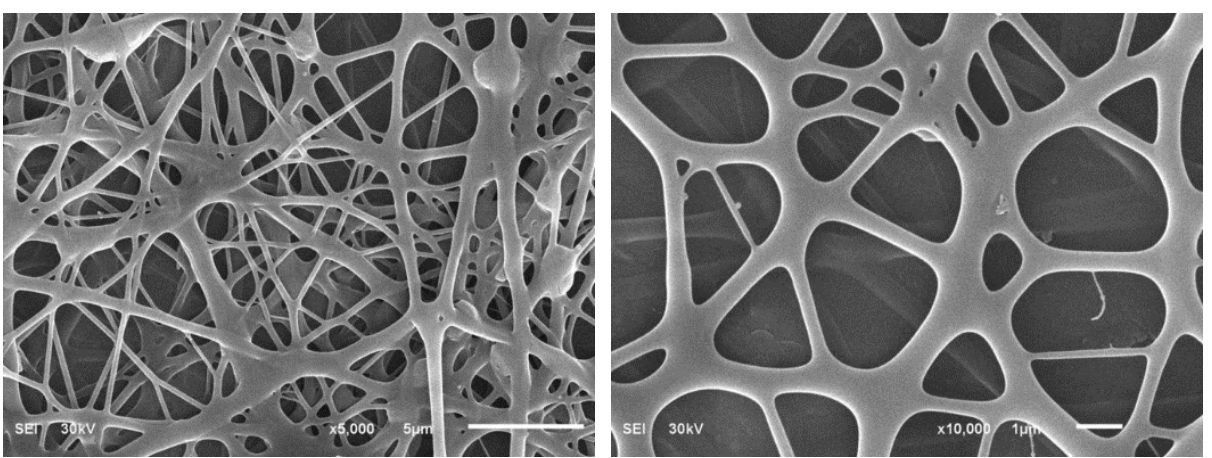

Fig. 2. SEM micrographs of the electrospun ferrite gel/PVP composite fibers.

Somewhat similarly, the SEM images of the obtained Ni-ferrite fibers after calcination and removal of PVP (Fig. 3.) depict a dense mat to the almost coral-like structure of fibers with diameters ranging from hundreds of nanometers to few micrometers. The shape of the observed ferrite fibers corresponds to the space within the electrospun composite fibers that were initially occupied by the ferrite gel. Also, shrinking of the polymer during the initial phase of calcination is the most probably responsible for their shrunken and deformed appearance.
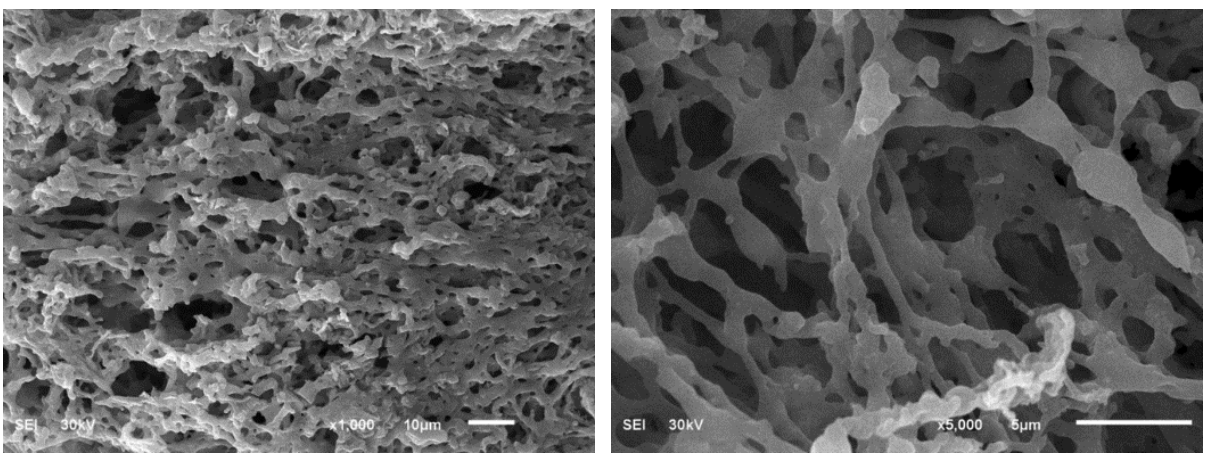

Fig. 3. SEM images of the obtained Ni-ferrite fibers after calcination.

Preliminary compositional analysis of the prepared Ni-ferrite fibers/mat using FTIR (Fig. 4.) has revealed presence of one $584 \mathrm{~cm}^{-1}$ and a hint of the other $\left(450-385 \mathrm{~cm}^{-}\right.$ ${ }^{1}$ ) of the two most important IR bands which correspond to intrinsic stretching vibrations of the metal at tetrahedral and octahedral sites of $\mathrm{NiFe}_{2} \mathrm{O}_{4}$ phase, respectively $[12,13]$. A 
broad absorption band with the peak at $3446 \mathrm{~cm}^{-1}$ represents the symmetric and antisymmetric -OH stretching as a consequence of the adsorbed water [14]. The peak at 2922 $\mathrm{cm}^{-1}$ combined with $2852 \mathrm{~cm}^{-1}$ also correspond to the $-\mathrm{OH}$ stretching $[14,15]$. The peak around $1638 \mathrm{~cm}^{-1}$ corresponds to the $-\mathrm{OH}$ bending of absorbed hydrates as reported in $[16,17]$. The set of peaks around $1270 \mathrm{~cm}^{-1}$ could also be attributed to the $-\mathrm{OH}$ deformation of moisture from the air [18]. It could be assumed that some of the peaks presented in Fig. 4 most probably do not belong to remnant organic compounds in the studied material due to the fact that the FT-IR observation is conducted after the calcination at $700{ }^{\circ} \mathrm{C}$ for $5 \mathrm{~h}$.

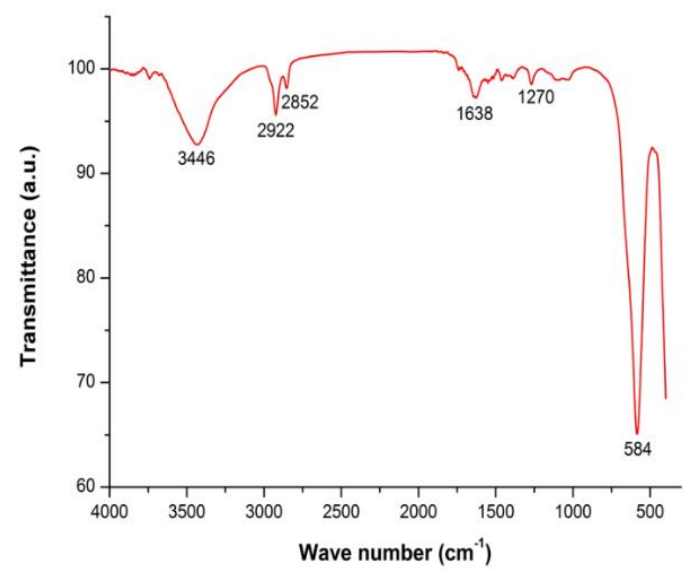

Fig. 4. FTIR spectrum of the prepared Ni-ferrite fibers/mat.

In order to determine the phase composition of the prepared fibers/mat XRD analysis was carried out and the obtained pattern is presented in Fig. 5. The results of XRD phase composition analysis confirm that the precursors were added in a stoichiometric ratio and that the pure $\mathrm{NiFe}_{2} \mathrm{O}_{4}$ material was obtained as the recorded XRD pattern contains all of the characteristic peaks (standard ICDD Ref. code 00-044-1485).

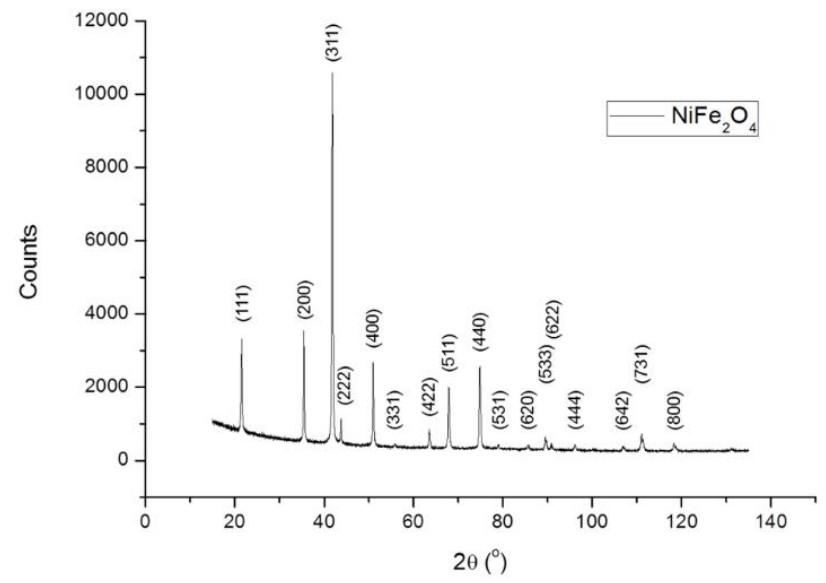

Fig. 5. XRD pattern of the obtained fibers/mat. 
For a more in-depth analysis of the prepared Ni-ferrite fibers/mat, additional characterization using room temperature ${ }^{57} \mathrm{Fe}$ Mössbauer spectroscopic analysis was carried out. The results of MS analysis confirm the formation of the nanocrystalline $\mathrm{NiFe}_{2} \mathrm{O}_{4}$ phase as the values of Mössbauer parameters determined from the recorded spectrum (Fig. 6.) are in a close agreement with those of $\mathrm{NiFe}_{2} \mathrm{O}_{4}$ phase from literature $[19,20]$. Accordingly, the related subspectrums were assigned to tetrahedral (A) and octahedral (B) iron $\left(\mathrm{Fe}^{3+}\right)$ atom sites.

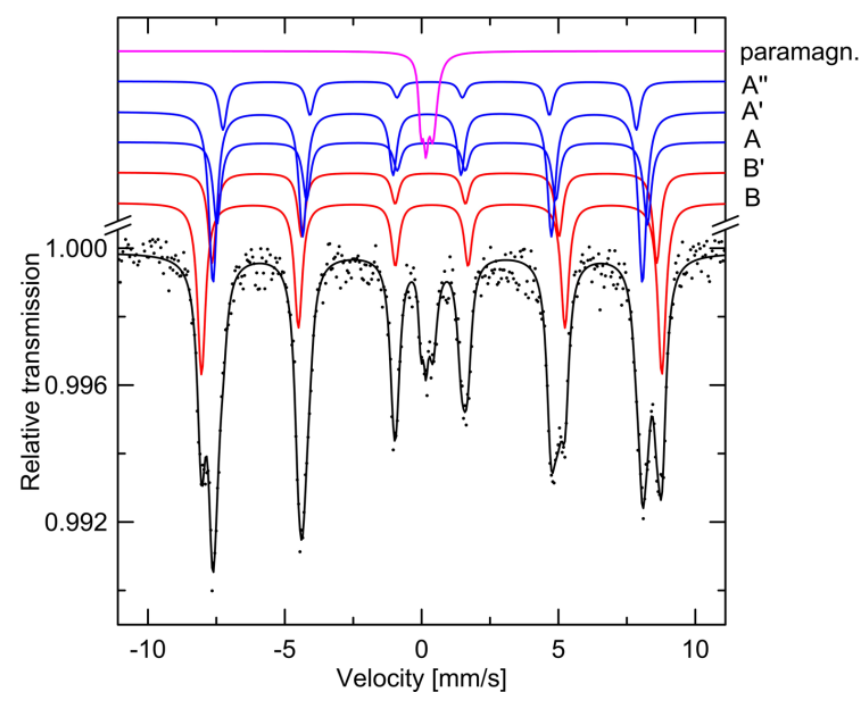

Fig. 6. Room temperature Mössbauer spectrum of the prepared Ni-ferrite fibers/mat.

The existence of the nanocrystalline structure of the identified $\mathrm{NiFe}_{2} \mathrm{O}_{4}$ phase is illustrated by the presence of a set of sextets with decreasing splitting and intensity that indicates the existence of a crystallite size distribution [21]. Also, a fairly small paramagnetic doublet that can also be observed points to the presence of a superparamagnetic fraction of the $\mathrm{NiFe}_{2} \mathrm{O}_{4}$ with very small crystallite sizes $<13 \mathrm{~nm}$ $[20,22,23]$.

The obtained thermomagnetic curves given in Fig. 7 provide clear insight into a thermomagnetic behavior of the prepared $\mathrm{NiFe}_{2} \mathrm{O}_{4}$ nanofibers mat. 


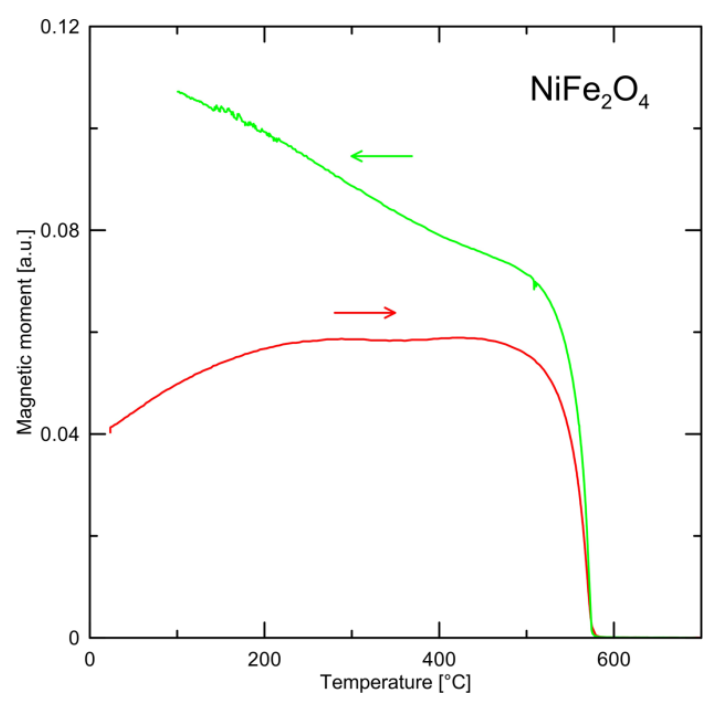

Fig. 7. The recorded thermomagnetic curves.

Although Ni-ferrite is ferrimagnetic material in its nature, at the beginning of the measurements it is not magnetized so initially, some small increase of the total magnetic moment can be observed on the heating curve. At about $200{ }^{\circ} \mathrm{C}$ it reaches a plateau, and then it swiftly drops at about $570{ }^{\circ} \mathrm{C}$ which matches the Curie temperature of $\mathrm{NiFe}_{2} \mathrm{O}_{4}$ phase. As expected, during the further heating up to $800{ }^{\circ} \mathrm{C}$ increased thermal energy causes atomic magnetic moments to oscillate randomly and thus there is no overall magnetization. Likewise, no changes can be observed on the cooling curve until $570{ }^{\circ} \mathrm{C}$ at which point a rapid and significant increase of the total magnetic moment occurs. With the further decrease in temperature, the magnetization follows the rising trend. This can be related to the fact that the material is cooling down in a magnetic field. Essentially, the magnetic moments try to minimize energy against the external magnetic field which results in an anisotropic moment distribution, that on a macro level manifests as an increase of an overall magnetic moment [24].

\section{Conclusion}

The joint sol-gel and electrospinning methods were successfully applied on selected precursor solution for as-spun ferrite/PVP nanofiber web preparation. After following calcination magnetic nanofibers with diameter from a few hundreds of nanometers up to micron sizes were obtained. The results of the conducted phase composition analyses clearly show that the nanocrystalline $\mathrm{NiFe}_{2} \mathrm{O}_{4}$ fibers were formed. Also, it can be assumed that there is a wider crystallite size distribution within the material with the smallest of them being below $13 \mathrm{~nm}$. Due to the specific nature of the obtained particles the thermomagnetic measurements were carried out in order to provide the magnetic behavior of such electrospuns at elevated temperature. The presented results of microstructural and phase analysis together with the conducted thermomagnetic behavior assessment suggest that the obtained $\mathrm{NiFe}_{2} \mathrm{O}_{4}$ nanofibers have enough potential to be used as such or as a filler in composite materials that can be useful for a variety of applications including magnetic nanostructures, separation, catalysis or even sensing elements. 


\section{Acknowledgment}

This work has been supported by the Ministry of Education, Science and Technological Development of the Republic of Serbia (Projects TR34011, III45019, ON172037)

\section{References}

[1] A. Ćosović, V. Ćosović, T. Žák, B. David, N. Talijan: J Min Metall B, 49(3) (2013) 271-277.

[2] S. Thenmozhi, N. Dharmaraj, K. Kadirvelu, H. Y. Kim: Mater Sci Eng B, 217 (2017) 36-48.

[3] Z.L. Wang, X.J. Liu, M.F. Lv, P. Chai, Y. Liu, J. Meng: J Phys Chem B, 112 (2008) 11292-11297.

[4] S.A. Corr, Y.P. Rakovich, Y.K. Gun'ko: Nanoscale Res Lett, 3 (2008) 87-104.

[5] J. Xiang, Y. Chu, X. Shen, G. Zhou, Y. Guo: J Colloid Interf Sci, 376 (2012) 57-61.

[6] H-S. Wang, G-D. Fu, X-S. Li: Recent Pat Nanotech, 3(1) (2009) 21-31.

[7] Y. Zhang, C. Teck Lim, S. Ramakrishna, Z. Huang: J Mater Sci-Mater M, 16 (2005) 933-946.

[8] D. Li, T. Herricks, Y. Xia: Appl Phys Lett, 83(22) (2003) 4586-4588.

[9] A. Sutka, G. Mezinskis: Front Mater Sci, 6(2) (2012) 128-141.

[10] H. Wu. W. Pan, D. Lin, H. Li: J Adv Ceram, 1(1) (2012) 2-23.

[11] T. Žák, Y. Jirásková: Surf Interface Anal, 38 (2006) 710-714.

[12] Y. Ahn, E.J. Choi, S. Kim, H.N. Ok: Mater Lett, 50 (2001) 47-52.

[13] N. Hanh, O.K. Quy, N.P. Thuy, L.D. Tung, L. Spinu: Physica B, 327 (2003) $382-$ 384.

[14] F.A. Miller, C.H. Wilkins: Anal Chem, 24(8) (1952) 1253-1294.

[15] N. Kanagathara, P. Shenbagarajan, C. Esther Jeyanthi, M. Thirunavukkarasu: Int J Pharm Biol Sci, 1(2) (2011) 52-56.

[16] N.A. Chowdhury, J. Robertson, A. Al-Jumaily, M.V. Ramos: J Appl Chem, 2014 (ID 474268) (2014) 1-6.

[17] H. El Swie, V. Radojević, 1. Brajović, J. Stajić-Trošić, V. Ćosović, A. Grujić, R. Aleksić: Dig J Nanomater Bios, 10(4) (2015) 1475 - 1483.

[18] M. Naeem Ashiq, M. Fahad Ehsan, M. Javed Iqbal, I. Hussain Gul: J Alloy Compd, 509 (2011) 5119-5126.

[19] V. Šepelák, D. Baabe, D. Mienert, D. Schultze, F. Krumeich, F.J. Litterst, K.D. Becker: J Magn Magn Mater, 257(2-3) (2003) 377-386.

[20] J. Jacob, A.M. Khadar: J App Phys, 107(114310) (2010) 1-10.

[21] J.M. Grenèche, M. Miglierini, in Mössbauer Spectroscopy in Materials Science, Eds.: Miglierini, M., Petridis, D., Kluwer, Dordrecht, 1999.

[22] H. Yang, L. Zhao, X. Yang, L. Shen, L. Yu, W. Sun, Y. Yan, W. Wang, S. Feng: J Magn Magn Mater, 271(2-3) (2004) 230-236.

[23] T. Komatsu, N. Soga: J App Phys, 51(1) (1980) 601-606.

[24] T. Žák, V. Ćosović, A. Ćosović, B. David, N. Talijan, D. Živković: Sci Sint 44(1) (2012) 103-112.

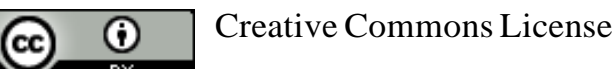

This work is licensed under a Creative Commons Attribution 4.0 International License. 